\title{
Rough Set and Conflict Analysis to Discover the Conflicts, Alliances and Neutralities among the Iraqi People Components
}

\author{
Huda Ahmed Abed \\ Iraqi Commission for Computers and Informatics/ \\ Informatics Institute for Postgraduate Studies
}

\author{
Hussein K. Khafaji, PhD \\ Professor \\ AL-Rafidain University College/Computer \\ Communication Eng. Dept.
}

\begin{abstract}
The democratic era in Iraq that began in Iraq after the spring of 2003 resulted in a conflict among political, ethnic, religious and nationalism components of Iraq. This paper provides an unprecedented research based on scientific foundations to discover the conflicts and alliances among the components of the Iraqi people and determine future Iraqi's tendencies. It depends on the concepts of rough set and conflict analysis. The research required many steps to be achieved. Such steps are: determining the Iraqi vital issues, creating what so-called "information system" database, (IS), submitting the IS to rough set and conflict theory depending on the general system for conflict analysis presented in [1], and modification of conflict model to predict the extension of "Enmity" and "friendship" concepts depending on the suggested algorithms and operations presented in [2].
\end{abstract}

Twelve vital issues were selected, depending on rough set's reduct operation, out of 31 issues. 5692 Iraqis, belong to eight Iraqi blocs, expressed their opinions about the selected issues. The opinions were attained using electronic opinion acquisition system prepared for this purpose. The participator's opinion may be positive, neutral, or negative. The research discovered 42,11 , and 43 positive, neutrals, and negative opinions respectively. However, the overall conflict situation was 17 alliances, 10 conflicts, and 1 neutral relation. The paper includes the prediction that the unique neutral relation would change to an alliance relation. The degree of the strongest conflict between two major Iraqi components was 0.9166667 , while the degree of the highest alliance between two Iraqi components is 0.04166667 .

\section{Keywords}

Rough set, conflict system, conflict analysis, Iraqi components, Iraqi conflict problem.

\section{INTRODUCTION}

This introduction will be divided into two ramifications; the first one is related to the rough set and conflict analysis and the second one presents an abstracted background related to Iraq political and social situation.

\subsection{Rough Set and Conflict Analysis}

The civil conflict may result from the variance of cultures, religions, social categories, interests, and living standards. Studying and analyzing the differences of views is extremely important since they may lead to more complex conflicts, which lead to divisions and clashes. The term conflict is one of the features of human nature. The conflict started from the beginning of human creation and it perhaps never terminated [3], [4], [5].

Conflict analysis plays an extremely significant function both in theory and in practice. It has been used in various important fields like trade, economic, e-commerce, governmental and political contention, games, management negotiations, military attacks and etc.[6], [7], [8], especially in areas that require decision making that have uncertainty problems. Conflict analysis, which goals to find out the kind of conflict, alliances, neutralities, and their strengths, has lately attracted raised attention [4], [9], [10]. There are many methods to process these problems using different approaches like Rough set [11].

In the situation of conflict, there is an ambiguity state around approval, neutrality and disapproval among agents. Rough set theory is an appropriate and effective tool to deal with this ambiguity and vagueness in conflict situation to make a decision. A binary relation is a main notion of rough set based conflict analysis, which summarizes this situation in an information system. In formal manner, a conflict relation can be considered as a particular type of discernibility, which is opposite of the indiscernibility relation. Indiscernibility is one of basic conception of rough set theory. It resembles the concept of conflict from a logical point of view [4]. Consequently, rough set theory is novel mathematical tool to handle ambiguity decision-making situations. It was used to study and analyze conflict decision making since late 90s. It does not require any further information unlike other mathematical tools when handling uncertain problems [12]. Huda et al, [1] proposed a general conflict analysis system depending based on rough set and conflict theory. This system has the ability to mine the "information system" to discover the conflicts, alliances, and neutral opinions for a given universe. It was used to analysis the Syrian conflict problem using many Syrian issues. The agents, in this problem, were the neighbor countries of Syria [3]. In addition, the system was used to analysis the data relating to the US presidential elections[https://wiki.csc.calpoly.edu/datasets/wiki/LargeTree].Hud a et al [2] proposed an algorithm to predict the changes that may occur in the agents' opinions. The algorithm depends on the graph theory and some of suggested operations on the adjacency matrices that are derived from the "information system" such as ORing, XORing, and ANDing. Combining 
the suggested algorithms presented in [1] and [2] leads to suitable environment to discover the conflicts in a given problem.

\subsection{Social and Political Background on \\ Iraq}

With the beginning of the 21 st century, social, technological, and political changes in the Middle East, especially in Iraq led to create a new sectarian trend. Some of these changes and factors that led to the creation of this trend are; the political change that took place in Iraq in 2003. In addition to the great proliferation of media and social networking techniques (Facebook was started in 2004, YouTube in 2005 and Twitter in 2006). Finally, the freedom from tyranny, oppression and suppression of freedoms, including freedom of opinion has been commenced. Thus, sectarian polemicists have become prevalent violently in social networks [13]. What happened in Iraq on April 9, 2003 was a great historic event. After fall the dictatorial regime, Iraq lived democratic improvement and a clear trend towards multi-party system which led to appearance of many movements and political parties that represent all nationalities, sects and components of Iraq, in addition to the individual's freedom to express his opinion. Therefore, a mind conflict and difference in point of views started among these parties and sects about the present Iraqi issues. Dispute and the difference in opinions about different issues between multiple sects and parties with conflicting interests had become a prominent [14]. Since President Saddam Hussein fell in 2003, the center of political conflict in the state was the competition between the Iraqis Shia and Sunna. Furthermore, the Arabic-Kurdish conflict and other nationality conflicts became more in deepness. Sectarian tenseness has prevented the construction processes and destabilized the region. In spite of the clear attempts of the government of Iraq to defeat these divides to construct the national identity that includes all nationalities and sects, the external interventions prevent the government efforts from attaining this goal. In the past, the cause of the conflict was about political, theological, and doctrinal issues, but now the new issues related to competition for power and resources has been appeared. These differences caused conflicts about the situation, population, boundaries, and power of each society that led to instability situation, particularly when they gave a legal description to the actions of extremist groups that claim to represent the societies [14].

With the beginning of 2014, Islamic State in Iraq and Sham (ISIS), an extremist group that is also present in Syria, managed to control the western lands of Iraq, disputed territories such as Ninewa, Kirkuk, Diyala, Anbar, and Salah al Din [15].

Briefly, the events of Iraq since 2003 until now (2017), showing that Iraq has suffered over these years of instability, invasion, internal war, bombings that harvested millions, sectarian violence which continued years and finally the seizure terrorist groups on some provinces, and thus mass exodus of families in those areas.
In 2017, after the liberation of most of the occupied provinces from these groups, a new issue surfaced, which is the demand of Kurds to total independence and the issue of the referendum to be conducted on it [16]. There are many historical and newly generated issues or problems in Iraq, which have unwanted impact on the civil peace and social union of Iraqis. During the preparation of this study, thirtyone issues are counted, but only twelve issues are selected as vital issues to be used in the research by using the reduct [17] of rough set. Table. 1 represents the most important and vital issues at the current stage Iraq.

Table 1. Issues list

\begin{tabular}{|c|c|}
\hline $\begin{array}{c}\text { Cod } \\
\text { e }\end{array}$ & Issue \\
\hline $\mathrm{a}$ & Positive opinion about popular mobilization forces \\
\hline $\mathrm{b}$ & The law of popular mobilization forces \\
\hline $\mathrm{c}$ & Establishment of Sunni region in Iraq \\
\hline $\mathrm{d}$ & Oil is own to all Iraqis without exception \\
\hline $\mathrm{e}$ & $\begin{array}{c}\text { The positive opinion about the liberation of the Iraqi } \\
\text { areas of ISIS }\end{array}$ \\
\hline $\mathrm{f}$ & $\begin{array}{c}\text { The Kurds takeover of Kirkuk without considering } \\
\text { the Article 140 of the Iraqi constitution }\end{array}$ \\
\hline $\mathrm{g}$ & Separation of Kurdistan Region \\
\hline $\mathrm{h}$ & Raising the Kurdish flag in Kirkuk \\
\hline $\mathrm{i}$ & $\begin{array}{c}\text { Change the members of Independent High Electoral } \\
\text { Commission }\end{array}$ \\
\hline $\mathrm{j}$ & $\begin{array}{c}\text { Representatives and the building of the presidency of } \\
\text { the Council of Ministers }\end{array}$ \\
\hline $\mathrm{k}$ & $\begin{array}{c}\text { Participation of some Iraqi political Figures in } \\
\text { meetings outside Iraq without knowing and } \\
\text { permission of the government }\end{array}$ \\
\hline $\mathrm{l}$ & $\begin{array}{c}\text { Inability of the Iraqi army and the Iraqi federal police } \\
\text { to spread in the provinces and regions without } \\
\text { obtaining their approval }\end{array}$ \\
\hline
\end{tabular}

\section{PROPOSED SYSTEM MODEL FOR IRAQ CONFLICT PROBLEM}

This section presents the analysis of the Iraqi conflict problem depending on the most vital issues; the issues that excite the concern and differences in views among Iraqis, they are presented in table.1. The analysis is accomplished using the general conflict system, which was suggested in [1] including its visualizer and the algorithm of opinions changes predictor which was presented in [2].

The proposed system in [1] is used to analysis the Iraqi conflict problem. Twelve vital issues are selected to study the Iraqi conflicts problem, recall Table.1. These issues are the most influent and have powerful impact on the Iraqis and making the mental conflict among them. The agents in this research are representing the Iraqi blocs that are mentioned in the Iraqi [18]. An electronic opinion acquisition system is designed to collect the opinions of Iraqis about these issues. There are 5692 participators categorized as shown in table. 2 Therefore, the agents are Sunnis, Shiites, Kurds, Sabean, Turkmen, Christians, Yazidi, and "Others". The "Others" category is specified for rare members of very small blocs such as Zardashti. In addition, some participators did not mention their nationality or religion. One or two participators 
write their religion as Atheist. These cases have been included in "Others" category. The converting process of the participators to categories is called granularity in rough set concepts.

Table 2. The number of voters in each Iraqi component

\begin{tabular}{|c|c|c|}
\hline Seq. & Iraqi component & Number \\
\hline 1 & Christian & 53 \\
\hline 2 & Kurd & 958 \\
\hline 3 & Shiite & 3023 \\
\hline 4 & Sunni & 1428 \\
\hline 5 & Sabee & 53 \\
\hline 6 & Turkmen & 140 \\
\hline 7 & Yazidi & 21 \\
\hline 8 & "Others" & 16 \\
\hline \multicolumn{2}{|c|}{ Total } & 5692 \\
\hline
\end{tabular}

Initially, the proposed system was executed to determine the conflicts, alliances, and neutrals according to a specific issue. An issue is selected in each time to build the "information system", IS, depending on the majority concept of conflict theory. After discovering the conflicts and alliances for each issue, the system discovers the alliances, conflicts, neutrals depending on all the issues. Table. 3 presents the opinions of the Iraqi components according to the specified issues.

The participator's opinions may be positive, neutral, or negative. (-1) means negative opinion, (0) means neutral, while (1) indicates positive opinion. The proposed general system for conflict analysis discovered 42, 11, and 43 negative opinions, neutrals, and positive opinions respectively. It is an important matter to mention is that the contents of Table. 3 depend on majority concept of rough set and conflict theory; therefore, it is necessary to consider the conflict in each political component or people entity. From the IS presented in Table.3, the majority of Kurd participators have negative opinions about of popular mobilization forces, issue a of table.1, which leads to same value about issue $b$. These opinions of the Kurd may attained from the concern of Kurds from the possible intervention of these forces in a conflict over the disputed territories. In addition, one can consider that the Christians have negative opinion about issue (a) because they believe that the popular mobilization forces are based on religious belief.
Table 3. Information system for all issues

\begin{tabular}{|c|c|c|c|c|c|c|c|c|c|c|c|c|}
\hline & $\mathbf{a}$ & b & c & d & e & f & $\mathbf{g}$ & h & $\mathbf{i}$ & G & $\mathbf{k}$ & I \\
\hline Christian & -1 & -1 & 0 & 1 & 1 & i & 0 & -1 & 1 & -1 & -1 & $i$ \\
\hline Kurd & -1 & -1 & 1 & -1 & 1 & 1 & 1 & 1 & i & -1 & 1 & 1 \\
\hline Others & 1 & 0 & i & 1 & 1 & i & -1 & -1 & 1 & 1 & -1 & i \\
\hline Sabee & 1 & 1 & $i$ & 1 & 1 & $i$ & -1 & -1 & 1 & 0 & -1 & i \\
\hline Shiite & 1 & 1 & i & 1 & 1 & i & -1 & -1 & 1 & 1 & -1 & i \\
\hline Sunni & 1 & -1 & 1 & 1 & 1 & 0 & -1 & 0 & 1 & -1 & 1 & 1 \\
\hline Turkmen & 1 & 1 & 0 & 0 & 1 & $i$ & -1 & -1 & 1 & -1 & 0 & 0 \\
\hline Yazidi & 1 & -1 & 1 & -1 & 1 & 1 & 1 & 1 & $i$ & -1 & 0 & i \\
\hline
\end{tabular}

The Sabee people are mostly matching the Shiite in their opinions because they are living in the same area; this matching creates an intellectual, cultural and economic convergence between the components, therefore, they own a positive opinions related to $a$ and $b$ issues. In spite of the objections of the Sunni people and their fear from popular mobilization forces, they expressed overwhelmingly in favor of these forces, issue a of table.1, because of this forces role in liberating the territory of Sunni people from ISIS. However, they do not want a law to legalize the popular mobilization forces, issue $b$, which may prolong legally the presence of these forces on the ground and on the political reality and they cannot deconstruct these forces without a new law issued from the Parliament. The Sunnis want to dismantle these troops after no need to its services.

Also, the Yazidis follow Kurds in most issues, because they regard themselves as Kurdish people. Therefore, most their opinions are similar.

Iraqi Turkmens are mixed-component; they composed of Shiites and Sunnis. Therefore, it believed that their opinions, in the IS above, are Sunnis' opinions and Shiites' opinions. In addition, it should be remembered that the Popular mobilization forces is the first Iraqi troops that hurry up to save the Turkmen areas, like Amerly, from the siege of ISIS, and this situation is, no doubt, formed a positive opinion about these forces. Table.4 stores the distance function which represents amount and strength of conflicts and alliances among the Iraqi blocs depending on the selected issues. Accordingly, the overall conflict situation was 17 alliances, 10 conflicts, and 1 neutral relation.

The unique neutral relation in table. 4 connects Sunni and Shiite, the two Iraqi components that seemed the most conflicted components according to their politicians' behaviors and declarations. This result is unexpected result that should be supported and empowered by the decision makers to achieve the civil peace. In addition, table. 4 depicts that the degree of the strongest conflict between two major blocs was 0.9166667 , this conflict is between Shiite and Kurd components and this result is unexpected due to the understandings among their politicians over the past years.

The degree of the highest alliance between two Iraqi components is 0.04166667 , which is held between Shiite and "Others" but this result is not important in case of comparing it with the Turkmen-Shiite alliance of strength equal to 0.25 because the majority of the Turkmens are Sunnis. 
Table 4. Distance function for all issues

\begin{tabular}{|c|c|c|c|c|c|c|c|c|}
\hline & Christian & Kurd & "Others" & Sabee & Shiite & Sunni & Turkmen & Yazidi \\
\hline Christian & & & & & & & & \\
\hline Kurd & 0.5833333 & & & & & & & \\
\hline "Others" & 0.2916667 & 0.875 & & & & & & \\
\hline Sabee & 0.2916667 & 0.875 & 0.08333333 & & & & & \\
\hline Shiite & 0.3333333 & 0.9166667 & 0.04166667 & 0.0416667 & & & & \\
\hline Sunni & 0.4166667 & 0.4166667 & 0.45833333 & 0.4583333 & 0.5 & & & \\
\hline Turkmen & 0.375 & 0.6666667 & 0.29166667 & 0.2083333 & 0.25 & 0.3333333 & & \\
\hline Yazidi & 0.5416667 & 0.2083333 & 0.6666667 & 0.6666667 & 0.7083333 & 0.4583333 & 0.5833333 & \\
\hline
\end{tabular}

Fig.1 depicts the conflict graph in which the vertices represent the Iraqi components while the alliances and conflicts are represented by dashed and bold lines respectively. The neutrality is represented by the absence of a line between two agents. To predict the future changes that may happened on the current Iraq situation, the next step is that the predictor, presented in [2], was used to discover the indirect alliances and conflicts and possible changes that may occur in agents alliances and conflicts. The results are shown in Fig.2. Fig 2$\mathrm{B}$ presented all the indirect alliances among the components. Fig.2-C shows the prediction of the system that the ShiiteSunni neutrality may change to an alliance. Fig.2-D shows the predicted Iraqi conflict situation in future according to these issues.Fig.1 showed that the Kurd have five conflicts out of seven agents and same saying is for Yazidi, and they are constructing an alliance. The Sunni component is in a neutral situation with these components. Fig.2-B shows the direct and indirect, predicted, alliances relations. The Figure includes two lobes of coalitions, the upper lobe is $\{$ Kurd, Yazidi $\}$ and the lower lobe involves \{Shiite, Turkmen, Sabean, Christian, and "Others" \}. The connector between these two lobes is the Sunni component, component No.6, i.e., it is possible to Sunni component to play an important role to create the environments of conflict normalization in Iraq.

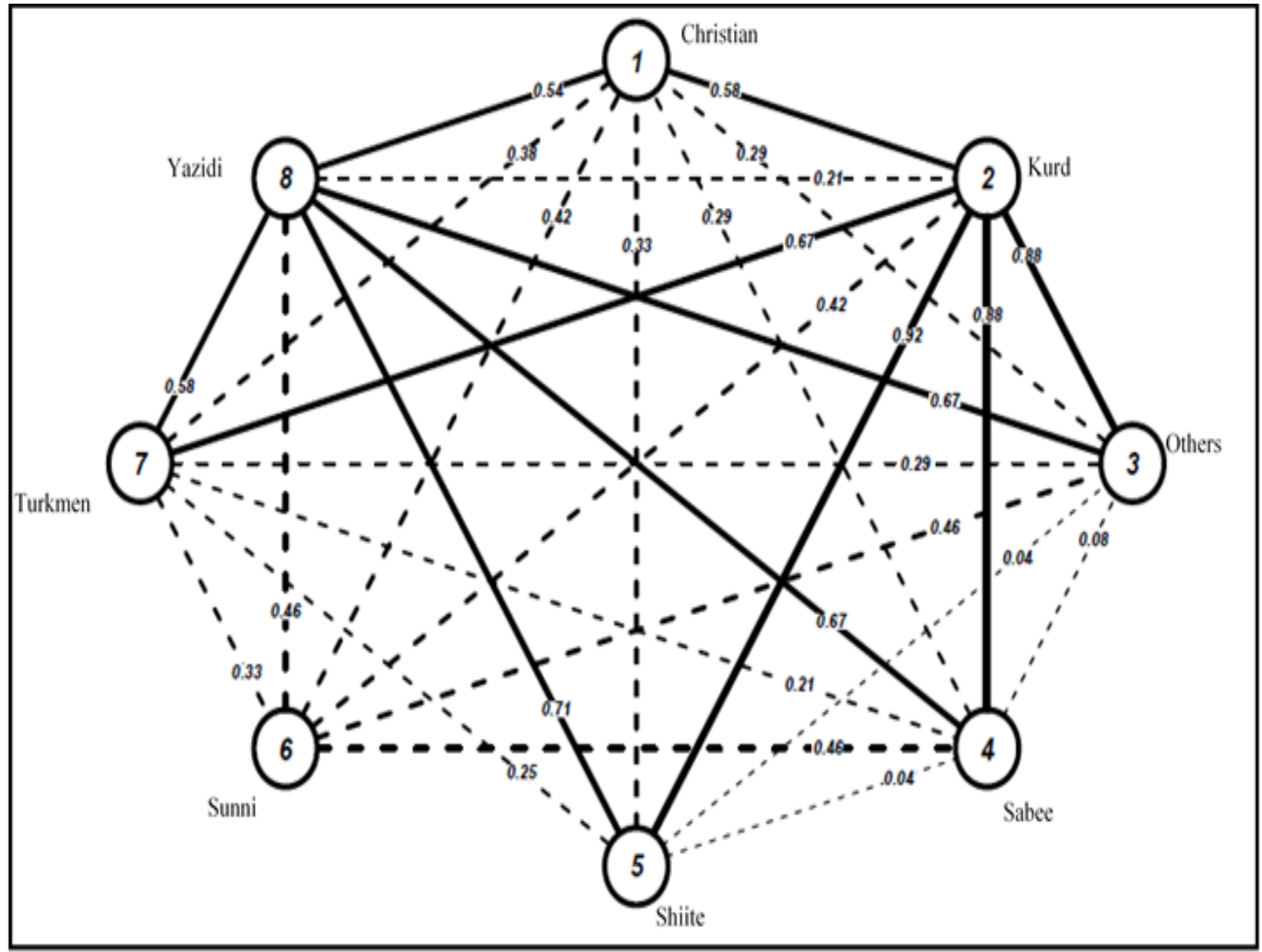

Fig. 1 Conflicts, neutrals and coalitions graph based on twelve vital Iraqi issues 


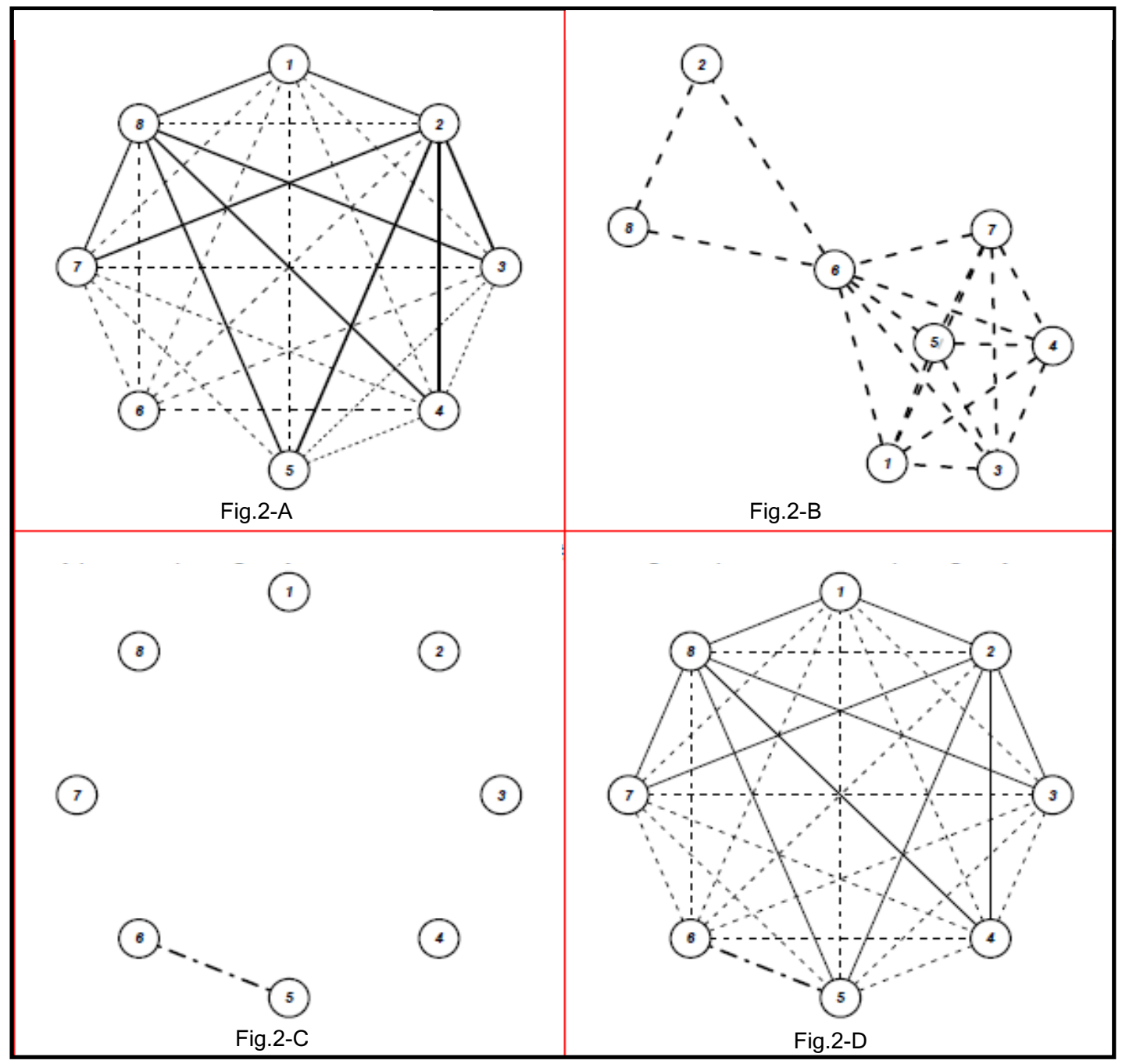

Fig.2 Conflict and coalition graph based on twelve issues

\section{CONCLUSION}

1. An important and unexpected conclusion that can be extracted from the result, consider Fig.1 and Table.4, is the neutral relation between the Sunni and Shiite components result from all issues. "It is neutral relation but it is of alliance flavor". The Shiite-Sunni conflict rooted in people's minds due to the politicians' declarations on media and criminal acts of extremist and terrorist groups. In addition, after applying the proposed prediction system, the neutral relation of SunniShiite is expected to be changed to an alliance relation; therefore, the decision maker should concentrate on the positive issues and find a common interest and supports the negotiation about the negative issues for actually converting the relation to the coalition relation.

2. The results showed that there are 10 conflicts, 17 alliances, and 1 neutral relation. If it omitted the 5 conflicts of the Yazidi bloc, which hold many ambiguities due to the fragmentation and displacement which they face, one can conclude that the alliances dominant the conflict in overall the situation in Iraq. Consider Table.4 and Fig.1.

3. The previous conclusions might be satisfactory about the situation in Iraq, but what a bummer is the degree of the conflict between Shiites and Kurds in the final outcome, which reaches more than 0.9 . That needs attention of the Iraqi Government and politicians from both blocs. Consider Table.4 and Fig.1.

4. The research discovered 42, 11, and 43 positive, neutral, and negative opinions respectively, which means rough balancing of conflict and alliance in Iraqi scene.

5. According to the results appeared in Fig.1, one can consider that the Turkmen as crossers to the concept of sectarianism and they attuned to their nationalism, such that they are in strongest conflict with Kurds of more than 0.6, an alliance with Sunni of more than 0.3, and remarkable alliance with Shiites equals to 0.25 .

6. According to the results appeared in table.4, one can conclude that Sunni is the owner of highest number of alliances, 6 alliances, 1 neutral relation, and no conflicts. Kurds and Yazidis have the highest number of conflicts, 5 conflicts, and 2 alliances for each. Christian and Turkmen have 2 conflicts and 5 alliances for each. Turkmen have strong conflicts with the Kurds and the Yazidis. Shiites have 2 strong conflicts, 4 alliances, and 1 neutral relation. 
7. From the results, one can conclude that each minor bloc in Iraq follows a specific major bloc that is in political, ethnic, religious, or geographic affinity with it.

8. A very important by-product gain from the research is building important database, which represents the opinion of simple but variant sample of Iraqi's related to some very vital issues.

9. Despite the length of the duration which is consumed to build the database but it could not be find some minority components' participants such as the Shabak component though this minority is living in a better-circumstances region than the Yezidis, where some members of Yazidi component participated in the opinion acquisition process.

10. To enrich the database, a live poll can be accomplished to mine the opinions of the refrained blocs.

11. The designed technique to collect the opinions of Iraqi people can be used in many future applications and research such as e-voting, e-reconnaissance, poll, or survey of opinion.

\section{REFERENCES}

[1] Hussein K. Khafaji; Huda Ahmed Abed, 2017. "Design and Implementation of a General System for Conflict Analysis," IOSR J. Comput. Eng., vol. 19, no. 5, pp. 1622.

[2] H. K. Khafaji and Huda Ahmed Abed, 2017. "Prediction of Changes That May Occur in the Neutral Cases in Conflict Theory Based on Graph Theory," nternational J. Comput. Sci. Inf. Secur., vol. 15, no. 9.

[3] M. C. Guangming Lang, Duoqian Miao, 2017. "Threeway decision approaches to confict analysis using decision-theoretic rough set theory." Information Sciences.

[4] B. Sun, W. Ma, and H. Zhao, 2016. "Rough set-based conflict analysis model and method over two universes," Information Sciences, vol. 372. pp. 111-125.

[5] Ho-Won Jeong, 2013. "Understanding Conflict and Conflict Analysis," Journal of Chemical Information and Modeling, vol. 53, no. 9. pp. 20-40.
[6] Z. Pawlak, 1998. "An inquiry into anatomy of conflicts," Inf. Sci. Elsevier scinece, vol. 109, no. 1-4, pp. 65-78.

[7] R. Deja, 2002. "Conflict Analysis.” INTERNATIONAL JOURNAL OF INTELLIGENT SYSTEMS.

[8] Z.-B. Xu, Daowu Pei, 2004. ."Rough Set Models on Two universes.pdf." International Journal of General Systems, Taylor \& Francis.

[9] L. G. D. O. Silva and A. T. De Almeida-Filho, , 2016. "A multicriteria approach for analysis of conflicts in evidence theory," Information Sciences, vol. 346-347. pp. 275-285.

[10] G. Guan, 2010. "Improved Pawlak conflict system and its application in the conflict problems of corporate governance," IEEE Intell. Syst.

[11] Z. Pawlak, 1982 "Rough sets,” Int. J. Comput. Inf. Sci., vol. 11, no. 5, pp. 341-356.

[12] X. Yang and J. Yang, 2012 "Incomplete Information System and Rough Set Theory."

[13] F. HADDAD, 2013 "Sunni-Shia Relations after the Iraq War Summary." UNITED STATES INSTITUTE OF PEACE PEACEBRIEF.

[14] [H. H. Al-Qarawee, 2014."IRAQ'S SECTARIAN CRISIS A Legacy of Exclusion." The Carnegie Middle East Center.

[15] B. Rohwerder, 2014. "Contemporary conflict analysis of Iraq.” GSDRC,International Development Department, College of Social Sciences University of Birmingham, B15 2TT, UK.

[16] "Iraq profile - timeline," bbc, 2017. [Online]. Available: http://www.bbc.com/news/world-middle-east-14546763.

[17] X. Jia, L. Shang, B. Zhou, and Y. Yao, , 2016. "Generalized attribute reduct in rough set theory," Knowledge-Based Systems, vol. 91. pp. 204-218.

[18] "Iraqi Constitution," General Secretariat for the Council of Ministers, 2005. [Online]. Available: http://www.cabinet.iq/PageViewer.aspx?id=2. 